Periodica Polytechnica Transportation Engineering, 50(1), pp. 49-57, 2022

\title{
The Influence of Education Level on Urban Travel Decision-making
}

\author{
Ali Enes Dingi $1^{1 \star}$, Domokos Esztergár-Kiss ${ }^{1}$ \\ 1 Department of Transport Technology and Economics, Faculty of Transportation Engineering and Vehicle Engineering, \\ Budapest University of Technology and Economics, H-1111 Budapest, 3 Múegyetem rkp., Hungary \\ ${ }^{*}$ Corresponding author, e-mail: ali.dingil@mail.bme.hu
}

Received: 17 July 2020, Accepted: 23 March 2021, Published online: 01 October 2021

\begin{abstract}
Personal choices can be changed by educating citizens. Education and learning are decisive factors in shaping the society and its spatial forms, where higher education level is an important proxy to assess the awareness level of people about current issues, such as sustainable transportation. Linking education and travel behaviour can inspire future urban policies to provide modal shift towards sustainable modes. The paper aimed to evaluate the influence of education level on mode choices for 45 cities from 29 countries. In general, education level was controlled by population density and GDP per capita, which are the parameters significantly influencing travel behavior. The main result has demonstrated that an increase in the higher education level is connected with dropping the modal share of driving in cities more than any change in other studied factors, while an increase in population density reduces driving more than an increase in GDP per capita. The results have been assessed and it was showed that higher education level considerably affects travel mode choice in cities. Thus, educating citizens is an important path to reduce car dependency.
\end{abstract}

Keywords

education level, modal share, travel behavior, travel decision-making, urban transportation

\section{Introduction}

\subsection{Importance of education}

Education is imparting, acquisition and construction of knowledge (e.g., know-what, know-why) including facts, representations, meanings and values as structured information about the world (André et al., 2012). Education and learning are decisive factors shaping the society and its surroundings in a dynamic way. Educating citizens was presented as one of the hopeful paths for providing sustainable development in one of the United Nations final reports (Carolee and Heather, 2014). The report indicated that learning and teaching are important themes, which are connected to climate change, and sustainability, which can increase the awareness level in a society and, in turn, this influences personal choices. A higher education level is an important proxy used in literature to assess the awareness level of societies with the current issues in a macroscopic way. An analysis was conducted to assess how attitudes of people and the education level are connected using a large cross-national database of the International Social Survey Program (ISSP) (Clery and Rhead, 2013). The obtained results showed that the level of education is well-correlated with environmental concerns, even when other socio-demographic factors were considered. Also, a report by OECD (Feinstein et al., 2006) demonstrated that the growing average education level improves the overall health care in a society. Transportation is a major reason of health issues and climate changes (International Energy Agency, 2011; Khreis et al., 2017), which indicates that education can influence travel patterns. Analyzing these connections and potential effects is valuable when creating future urban polices.

\subsection{Background}

One research was conducted using the Dutch National Travel Survey database of 28419 senior citizens (people aged 50 and over) to examine various leisure activities (Schwanen et al., 2001). The analysis demonstrated that the education level is positively correlated with public transport mode choice for leisure trips. A paper investigated how some characteristics in a society affect the travel mode choice based on the travel survey conducted in the Netherlands dataset for the 6630 long distance 
trips (Limtanakool et al., 2006). The results confirmed that highly educated commuters showed the highest tendency to travel by public transportation, instead of travelling by car. One cross-sectional work studied commute mode choices in southern Sweden in 2012 based on a survey conducted with 7574 commuters (Mattisson et al., 2018). The results demonstrated that the urban mode share of highly educated commuters was the highest for public transit, followed by non-motorized modes, and private vehicles.

One study analyzed non-motorized commuting based on the American Housing Survey in which 3243 commuters participated (Plaut, 2005). The analysis demonstrated that the non-motorized commuters were higher educated than car commuters, especially in the case of cycling. Another paper focused on predicting walking and cycling modal shares based on a dataset from the Netherlands, containing 2000 households (Ton et al., 2019). The results indicated that higher educated people utilized bike more than people with a lower education level. Another study was conducted in urban areas of the United States to investigate socio-environmental factors and individual attitudes regarding how people use bikes (Handy et al., 2010). Higher education was positively correlated with cycling.

Car-sharing is one of the key strategies aiming at reducing car usage. One study investigated how the membership potential of car-sharing programs and the socio demographic factors were connected in Quebec City for 4764 members (Coll et al., 2014). The obtained results indicated that car-sharing was widely used only by certain user groups, such as people with higher education. Similar findings were observed in another study, where a survey of 2800 people in the US was analyzed, in which the highly educated participants had a higher tendency to use car-sharing services (Dias et al., 2017).

\subsection{Aim of the study}

There is an abundant amount of mode choice analysis in literature considering many socio-demographic variants. However, the least pronounced one is the education level. The related literature represents only the side findings of the researches and local analysis. Our hypothesis is that highly educated communities would put a higher value on protecting the environment in connection with supporting more sustainable ways of transportation. To test this, we consider the higher education level as the basis of the study and conduct a global analysis to ensure a broad overview. The aim was to assess the effect of higher education level on travel mode choice for 45 urban areas from
29 countries. Additionally, higher education level was controlled by Gross Domestic Product (GDP) per person and population density of the cities, which significantly influence travel behavior. The manuscript is structured in the following way: Section 2 is about data collection, data processing and the applied methods. The results are shown in Section 3. Then the discussion is processed in Section 4, finally Section 5 provides a summary.

\section{Methodology}

\subsection{Data collection and processing}

This study aimed to assess an open and comparable dataset from major global cities and to process and correlate the collected data. Mode choice, higher education level, population density, GDP per capita and other parameters have been used, 45 cities from 29 countries were examined.

Commuting modal share of the urban areas was collected from different sources, such as regional statistical offices and local studies. The dataset for the car modal share, the public transportation modal share and the active modal share was deducted using a few sources (Eurostat; Development Bank of Latin America (CAF); European Platform on Mobility Management; United States Census Bureau; Fietsberaad, 2009; Land Transport Authority, 2014; Città Metropolitana di Bologna; Seoul Metropolitan Government; Sootfreecities) for various cities between 2008 and 2016.

Higher education level (EDU) data is interpreted as post-secondary attainment for inhabitants between 24-64 years old and collected from many reports (Eurostat; Development Bank of Latin America (CAF); Seoul Metropolitan Government; United States Census Bureau; National Statistics Center, Japan) for the cities. All data is expressed as the percentage of post-secondary attainment. However, the quality of education is not considered in this study which may cause some inaccuracy.

Population density and GDP per capita were also considered as other major factors, since urban form and economy level have high influence on travel patterns, which has been demonstrated in a high number of studies (Bhat, 1997; Chen et al., 2008; Crane, 2000; Dingil et al., 2019a; Ewing and Cervero, 2010; Handy, 1996; Hensher and Rose, 2007; Limtanakool et al., 2006; Santos et al., 2013; Vasconcellos, 2005). These factors are collectively referred to urban indicators. Gross Domestic Product (GDP) per person and population density databases are used from a paper (Dingil et al., 2018) considering the cities. Population density used as population per square kilometres and the values of GDP were represented as an 
average value considering 2010-2014 in US dollar. In the case of some cities, where GDP per capita and population density were missing, the dataset was provided using some reports (Bouchet et al., 2018; Citypopulation). Some inaccuracy may occur due to the data compatibility problems, which are the data mixing resulting from using various open source databases and from using specific years.

\subsection{Applied methods}

The method of measuring correlation was conducted to identify the potential connection between travel mode choice and other urban variables. Correlation method is a bivariate analysis and there are three types of correlation methods commonly used in literature that are Pearson, Kendall and Spearman. The strength and the direction of association between two variables can be measured by correlation analysis. Spearman and Kendall rank correlation measures are non-parametric tests measuring the degree of monotonic relationship that do not have any assumptions about the data distribution while Pearson correlation measure is a parametric test measuring the degree of linear relationship with the consideration of the data distribution. Spearman and Kendall measures are the proper representative methods for the ranked data and should not be over interpreted as a significant measure for the direct relationship (Hauke and Kossowski, 2011). Also, the correlation coefficients of Pearson, Kendall and Spearman measures are generally close to each other, therefore the safer approach to take into account is the lower value (Hauke and Kossowski, 2011). Following these, the Pearson correlation method was used in the analysis section here as our database is original numeric (not ranked) and the correlation coefficient values was lower for the Pearson coefficients. Similar approach has been used in travel behavior literature for numerous other cases (Hunecke et al., 2001; Matthies et al., 2002; Garvill et al., 2003; Klöckner and Matthies, 2004; Klöckner and Blöbaüm, 2010; Dingil et al., 2019b). The Pearson Correlation Analysis is the best method of measuring the strength of a linear association between two variables as the method is based on covariance. The Pearson correlation value varies between +1 and -1 . The Pearson correlation coefficients are interpreted in Section 3, thereafter we also tested the linearity assumption with a scatterplot for the highest correlation value (the car mode share over the higher education level). In case of high correlation coefficients between modal share and other urban variables, the multiple linear regression modelling was conducted to predict modal share. Linear regression attempt is a type of predictive analysis, which supports modelling the linear connection of variables (independents and dependent ones). This is realized by adjusting a linear equation using the observed dataset. The approach was to estimate the dependent variable and used to determine the strength of predictors and the impact of predictor changes on the dependent variable. The car modal share was predicted under a perfect statistical significance with the multiple linear model. Thereafter, the assumptions of normality and the absence of multi-collinearity has been tested in order to understand how the multiple linear model is reliable to predict the car modal share. Normality test was performed in order to understand weather the independent variables are distributed normally or skewed. The test was used to determine how much violation occurs from the distributed independents when dealing with small dataset. Multi-collinearity test was used to measure a state of inter-correlations among the independent variables. The occurrence of high inter-correlations among independent variables can lead to skewed or misleading results.

\section{Analysis and results}

In this part of the paper, an analysis conducted to understand the influence of the higher education level on the urban travel mode choice with considering other urban indicators in the investigated cities is presented.

\subsection{Correlation analysis}

In the first step, the Pearson correlation coefficients between higher education level, GDP value, population density, and travel mode choices were analyzed using the dataset, then the results were assessed. Afterwards, a modeling task were performed including mode choices based on the higher education level while considering GDP values and population density. The SPSS 25 software was used during the calculations to conduct an analysis with Pearson correlation and linear regression, while the $95 \%$ confidence level was considered. Table 1 shows correlation values between indicators while low correlation values, whose coefficients are below 0.2 , were not presented.

Table 1 Coefficients of the Pearson correlation (R) of mode choice and variables in an urban environment.

\begin{tabular}{lccc}
\hline & $\begin{array}{c}\text { Education } \\
\text { level }\end{array}$ & $\begin{array}{c}\text { Population } \\
\text { density }\end{array}$ & $\begin{array}{c}\text { GDP per } \\
\text { capita }\end{array}$ \\
\hline Car \% & -0.684 & -0.625 & 0.367 \\
Public transport \% & 0.619 & 0.594 & -0.329 \\
Bike \% & 0.450 & 0.651 & - \\
Walking \% & 0.455 & 0.598 & -0.412 \\
\hline
\end{tabular}


As a result, a strong negative correlation between the higher education level and driving can be seen in Table 1 . Therewithal, the level of education has a positive correlation with public transport usage and active modes. These results confirm previous findings between the education level and the mode choice (Schwanen et al., 2001; Limtanakool et al., 2006; Ton et al., 2019), however in our case with comparable data providing a holistic view. The background of the results can be that individuals of higher educated societies buy fewer cars, drive less, and use sustainable transport systems more due to environmental and health concerns.

Note that on a general level we did not find any significant correlation between GDP values and level of higher education. However, a relevant connection between higher education level and population density was found with a coefficient of 0.52 . This finding suggests that highly educated people live in a more densely populated cities.

As expected, population density has significant impact on mode choice. A positive correlation between PT (public transport) share and population density was found. Also, a high correlation of negative aspect was observed between car modal share and population density. The highest correlation with the population density is seen for the combination of active modes (walking + bike) with a coefficient of 0.73 . Furthermore, the economy level is moderately correlated with mode choice. In cities with higher GDP per capita people drive more, use public transport less and walk less at a moderate level. However, there is no significant correlation between cycling and GDP per capita.

\subsection{Regression analysis}

To provide more detailed results considering the linear assumption, car modal share and higher education level were presented in a scatter graph. Fig. 1 demonstrates the negative linear relationship between car modal share and education level with presented city labels. A similar relationship but with a negative aspect was observed between the public transport modal share and education level with a slightly lower $\mathrm{R} 2$ value. The most beneficial connection of the education level and car modal share is provided with the shape of a linear function as defined in Eq. (1):

Car share $=\mathrm{c}+\mathrm{d} *$ EDU.

As it can be observed in Fig. 1, the evaluated cities can be divided into 3 typical geographical regions. Cities from the USA have in general higher car modal share, mostly between 80 and $90 \%$. Washington has the highest education rate with a more than $50 \%$, and one of the lowest car usage percentage, which confirms our assumptions in this paper. However, this value is still $75 \%$, which is considerably higher than in case of other continents. In addition, New York is not a typical American city, where the car modal share is only $55 \%$, mostly because of its very well-developed public transport system.

In the case of Europe, the average car modal share is between 30 and $50 \%$. In most cities the basic correlation between higher education level and car modal share values are valid. For example, in Budapest the education level is $38 \%$ and car has $35 \%$, and in Helsinki the education level is $48 \%$ and car modal share has $49 \%$, which is quite straightforward. This positive effect of higher education on sustainable mode choice is strongly apparent in Zürich, where citizens are highly educated (58\%) and at the same time having low car usage values (33\%). In case of Rome, the education level is very low (27\%), which is associated with a high level of car usage (50\%), but it does not reach the American values by far.

A few cities from Asia were also assessed. They confirm the theory of the paper, however, the differences are bigger. Tokyo is a perfect example of highly educated citizens $(67 \%)$ and low car modal share $(12 \%)$. In case of Hong Kong the higher education level is moderate (47\%), but the car usage is extremely low ( $8 \%$ ), which is caused by economic and strategic regulations in the city.

To assess the mode choice in cities, multiple regression models were applied on the dataset, which contains the higher education level (EDU), the GDP value per person (GDP), and the population density (PD) that showed a significant correlations with the car mode share (Eq. (2)) and the public transport share (Eq. (3)):

$$
\begin{aligned}
& \text { Car share }=\mathrm{c}+\mathrm{d} * \mathrm{EDU}+\mathrm{e} * \mathrm{PD}+\mathrm{f} * \mathrm{GDP}, \\
& \text { PT share }=\mathrm{c}+\mathrm{d} * \mathrm{EDU}+\mathrm{e} * \mathrm{PD}+\mathrm{f} * \mathrm{GDP},
\end{aligned}
$$

Model 1 and Model 2 were expressed above with the Eqs. (2) and (3), respectively. $\mathrm{R}^{2}$ of the presented models are 0.62 and 0.52 , respectively. $R$ squared values are used to understand how well the multiple regression models fit the dataset. Both models present a good level of prediction. The predictor variables explain $62 \%$ of the variability of the dependent variable in Model 1 while the predictor variables explain $52 \%$ of the variability of the dependent variable in Model 2. Also, Table 2 and Table 3 demonstrates ANOVA tables testing whether multiple regression models present a goodness of fit for the dataset. 


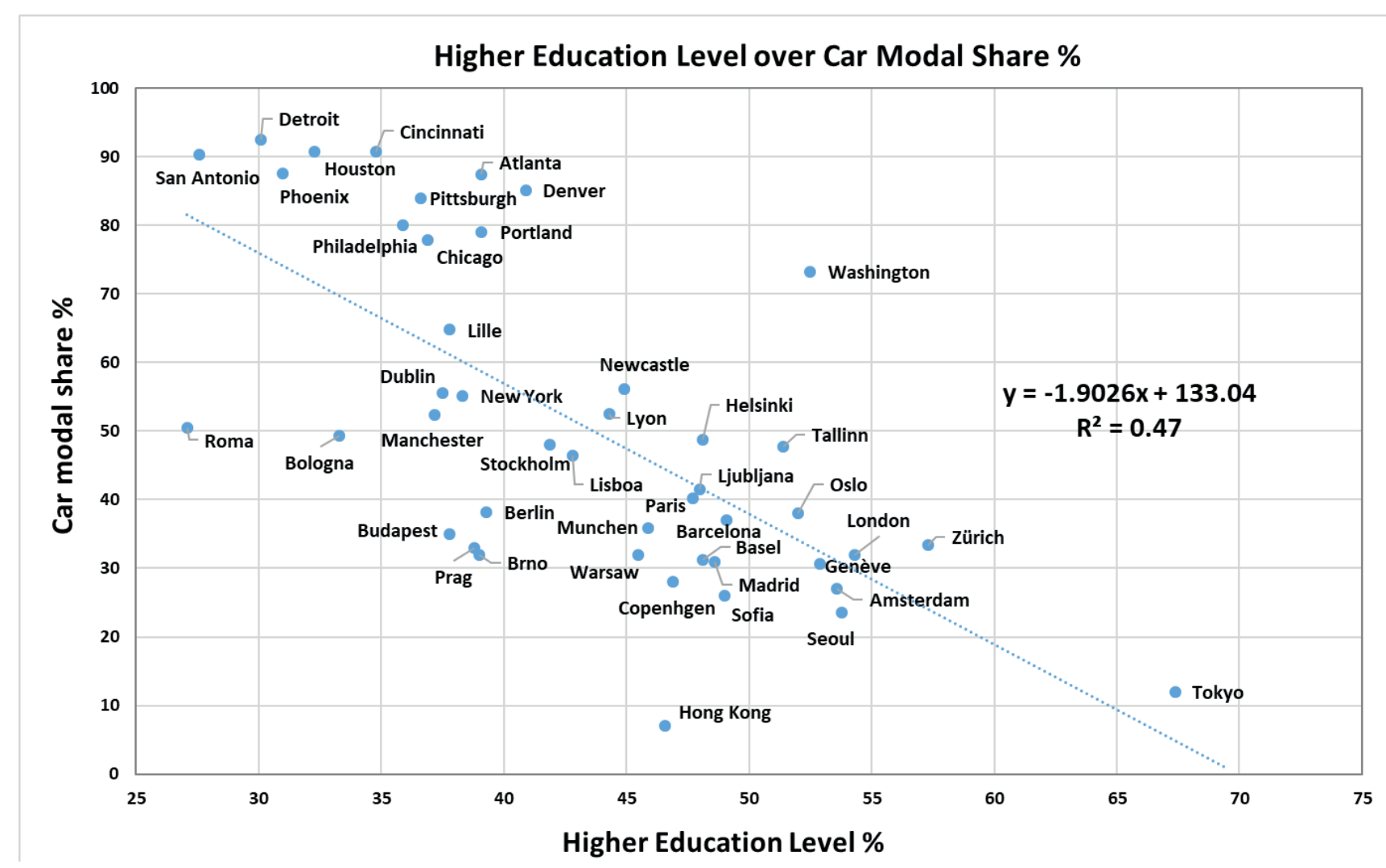

Fig. 1 Higher education level and the car modal share.

Table 2 ANOVA results (Model 1)

\begin{tabular}{|c|c|c|c|c|c|c|}
\hline \multicolumn{2}{|c|}{ Model 1} & Sum of squares & $\mathrm{df}$ & Mean square & $\mathrm{F}$ & Sign. \\
\hline \multirow{3}{*}{1} & Regression & 15218.107 & 3 & 5072.702 & 22.228 & 0.000 \\
\hline & Residual & 9356.767 & 41 & 228.214 & & \\
\hline & Total & 24574.875 & 44 & & & \\
\hline \multicolumn{7}{|c|}{ Table 3 ANOVA results (Model 2) } \\
\hline \multicolumn{2}{|c|}{ Model 2} & Sum of squares & df & Mean square & $\mathrm{F}$ & Sign. \\
\hline \multirow{3}{*}{2} & Regression & 7434.750 & 3 & 2478.250 & 14.309 & 0.000 \\
\hline & Residual & 6928.022 & 41 & 173.201 & & \\
\hline & Total & 14362.773 & 44 & & & \\
\hline
\end{tabular}

F-tests of the multiple linear regression have null hypothesis where the presented models express zero variance in the predictor variables. The $\mathrm{F}$ ratios are statistically significance that the regression models present a significant amount of the variance $(p<0.05)$. Both tables shows that the predictor variables predict the mode choice variable with a high significance. Both models are a good fit of the data. Table 4 and Table 5 demonstrate coefficients tables. Unstandardized coefficients (B) and the standardized coefficients (Beta) are used to indicate how much the mode choice vary with any predictor variable when all other predictor variables were held constant. The units of the parameters are different, for this reason, we took into account standardized Beta coefficients for assessing and comparing. The parameter presented in the tables: c, $\mathrm{d}$, and e were to explain any change in the modal share due to an increase or decrease in the predictor variables. This represents how much change occurred in the dependent variable for each unit of change in the predictor variables (independent) while p-values determine whether the observed relation can also exist in the larger same size. The tables present outcomes of t-tests when using the specific 
Table 4 Coefficient results (Model 1)

\begin{tabular}{|c|c|c|c|c|c|c|}
\hline \multirow{2}{*}{ Model 1} & & \multicolumn{2}{|c|}{ Unstandardized coefficients } & \multirow{2}{*}{$\frac{\text { Standardized coefficients }}{\text { Beta }}$} & \multirow{2}{*}{$\mathrm{t}$} & \multirow{2}{*}{ Sign } \\
\hline & & B & St.error & & & \\
\hline \multirow{4}{*}{1} & (Constant) & 99.60 & 15.344 & & 6.491 & 0.000 \\
\hline & $\mathrm{EDU}-\mathrm{C}$ & -1.373 & 0.313 & -0.493 & -4.382 & 0.000 \\
\hline & PDEN - D & -0.003 & 0.001 & -0.315 & -2.734 & 0.009 \\
\hline & GDP - E & 0.000 & 0.000 & 0.233 & 2.347 & 0.024 \\
\hline
\end{tabular}

Table 5 Coefficient results (Model 2)

\begin{tabular}{|c|c|c|c|c|c|c|}
\hline \multirow{2}{*}{ Model 2} & & \multicolumn{2}{|c|}{ Unstandardized coefficients } & \multirow{2}{*}{$\begin{array}{c}\text { Standardized coefficients } \\
\text { Beta }\end{array}$} & \multirow{2}{*}{$\mathrm{t}$} & \multirow{2}{*}{ Sign } \\
\hline & & B & St.error & & & \\
\hline \multirow{4}{*}{2} & (Constant) & -3.700 & 13.368 & & -0.277 & 0.783 \\
\hline & $\mathrm{EDU}-\mathrm{C}$ & 0.919 & 0.278 & 0.490 & 3.308 & 0.002 \\
\hline & PDEN - D & 0.002 & 0.001 & 0.312 & 2.327 & 0.025 \\
\hline & $\mathrm{GDP}-\mathrm{E}$ & 0.000 & 0.000 & -0.201 & 2.347 & 0.089 \\
\hline
\end{tabular}

regression models (multiple linear) of $\mathrm{N}$ sample sizes. The t-test results were only demonstrated for the car modal share and the public transport modal share predictions, because the statistical significance was very low for the estimation of other modes. One can see the significance of $\mathrm{t}$ test from Table 4 that all predictor variable coefficients are statistically significance for Model $1(\mathrm{p}<.005)$. Also, the higher education level and population density is statistically significance for the Model $2(p<0.05)$ while GDP per capita is near significance $(\mathrm{p}=0.08)$ in Table 5 . Nevertheless, the intercept, B0, is not statistically significance for Model 2. The Model 1 provided an outcome that the higher education level has a higher effect on dropping the car modal share in cities than population density and GDP per capita. An increase in higher education level reduces the car modal share 2 times more than an increase in GDP per capita boosts it. Looking into significant coefficients in the Model 2, we can assume that an increase in higher education level increases the public transport modal share more than an increase in population density.

As the Model 1 is totally statistically signaficance, we further provided additional statistical tests. Fig. 2 shows that P-P plot for the regression of the multiple linear function model of Eq. (2). The plot graph determines, whether the residuals are normally distributed or not. The plot indicates that there is no drastic deviation and the model residuals follow a normal distribution.

Table 6 demonstrates the Variance Inflation Factor (VIF) and tolerance values from multi-collinearity test results for Eq. (2). The VIF measures the extent of correlation between one independent variable and the other independent variables in the presented model. Since the value of

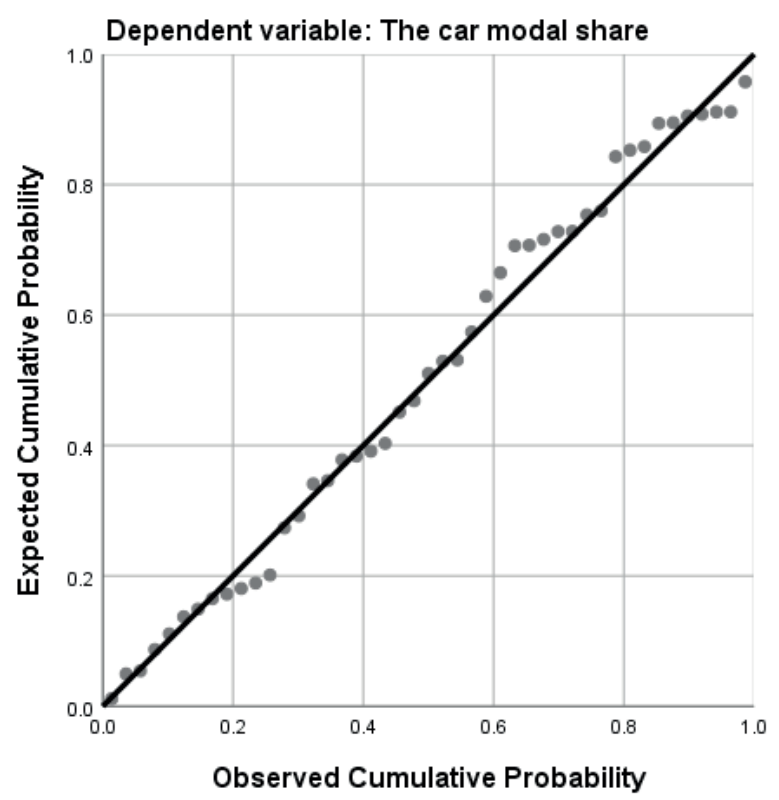

Fig. 2 The P-P plot of regression standardized residual for Eq. (2).

Table 6 Results of multi-collinearity test for Eq. (2).

\begin{tabular}{lcc}
\hline & Tolerance & VIF \\
\hline D & 0.733 & 1.364 \\
$\mathbf{E}$ & 0.702 & 1.425 \\
$\mathbf{F}$ & 0.943 & 1.060 \\
\hline
\end{tabular}

tolerance and the Variance Inflation Factor are the inverses of each other, 1 means that the predictor is not correlated with other variables while the value 10 represents the maximum level of VIF, which shows that independent variables are highly correlated. As VIF value increases and tolerance value decreases, the less reliable the regression results are going to be. As seen in Table 6, each VIF value is below 5 
and tolerance value is above 0.2 , indicating that the prediction of car modal share is met perfectly.

\section{Discussions}

Social scientists and artists define the topicality of their citizens using a specific interpretation (Van der Borg and Russo, 2005). One recent quantitative analysis investigated the consequence of cultural background on urban travel patterns in worldwide cities from 41 countries using Hofstede's culture parameters (Dingil et al., 2019b). The results has shown that urban travel patterns were influenced significantly by Hofstede's three culture parameters. The first one is called individualism vs collectivism, the second one is uncertainty avoidance, and the third one is masculinity vs femininity. These three parameters presented in Hofstede's study (Hofstede, 1980) were defined as follows. The first parameter was stated as the basic culture dimension that represents the interdependence degree in a society. Societies with a low degree of this parameter are highly collective communities, which have willingness to act together. The second parameter was identified as the degree of built-in worry of a society. Societies having high value of this parameter have also high level of concerns in specific situations. The third parameter describes the level of competitiveness in a community, which has to be considered as a relevant issue. However, a more feminine cultures are more likely to be concerned with the quality of life in cities in general.

The results of research (Dingil et al. 2019b) revealed that cultural circumstances are effecting travel behavior in an urban environment. High correlation values showed that a more individual transportation environment is being created in locations, where higher individualistic approach is present which results in more car usage. Typically, the following countries have such scores: United Kingdom, USA, NZ (New-Zealand), Australia, Canada, Italy. Conversely, the public transport modal share is higher in case of countries with a collective attitude. Typically the following countries have such scores: Brazil, China, Colombia, Hong Kong, South Korea, Peru, and Thailand. In addition, it could be observed from the multiple regression model presented in (Dingil et al., 2019b) that in case of countries with simultaneously higher scores of collectivism, masculinity and uncertainty parameters have in general higher values in PT usage. However, some countries with high individualism show a tendency to adapt to biking. Notable examples are Denmark and the Netherlands in which car and public transportation modal shares are low in comparison with other nations, although individualism scores are high, still, these nations have the greatest bike use among all countries.

Besides culture, education level can be called as "acquired characteristics" of a society shaping the citizens and its spatial forms in dynamic collective ways. Culture and education level are both decisive factors. Therefore, merging the results of both findings can support understanding of the topic in a more holistic way. We can shape inherited biases only with educating citizens. Our results have demonstrated that there is significant influence of the education level on private vehicle usage.

As stated, some countries with high individualism show a tendency to use bikes such as Denmark and the Netherlands where the education level is high. These countries had very high car usage during 1970s and their modal transformation to cycling occurred in last decades with increased environmental concerns as well as cycling can be named as "environmental friendly individualistic mode". So, following these, this is not surprising at all, this can be called as an effect of education level. While countries exhibiting the highest individualism have the highest car modal share. However, considering that the UK has the highest education level among these countries and the UK is the country with the lowest car modal share. Furthermore, some South American and Asian countries have highest values for collectivism and also high PT modal share. In addition, South Korea and Hong Kong have one of the highest educational levels among these countries and in the same time these countries have the highest PT usage. Thus, education can be called an "antidote" for the cultural biases in travel behavior. Specific educational seminars related to current transportation issues can be organized regularly by local authorities to increase awareness of the citizens and to support travel behavior change in more sustainable manner.

\section{Conclusions}

The influence of higher education level on urban travel mode choices was examined with a large and diverse open data collection of 45 cities distributed over 30 countries. The main result has demonstrated that an increase in higher education level has higher effect on dropping car modal share in cities than any change in GDP value and population density. If the population density parameter is lower, then in general car modal share increases, more than an increase in GDP per capita boasts car usage. It was observed in this research that higher education level has a considerable effect on travel mode choices in communities. Presumably, higher educated 
societies buy less cars, drive less and use alternative mobility systems more due to environmental and health concerns. Additionally, the effect of culture in urban travel patterns was discussed. This study has demonstrated that educating

\section{References}

André, I., Carmo, A., Abreu, A., Estevens, A., Malheiros, J. (2012) "Learning for and from the city: the role of education in urban social cohesion", Belgeo, 12(4), pp. 1-19. https://doi.org/10.4000/belgeo.8587

Bhat, C. R. (1997) "Work travel mode choice and number of non-work commute stops", Transport Research Part B: Methodological, 31(1), pp. 41-54. https://doi.org/10.1016/S0191-2615(96)00016-1

Bouchet, M., Liu, S., Parilla, J., Kabbani, N (2018) "Global Metro Monitor 2018", Brookings Instituion, Washington, DC, USA, [online] Avaliable at: https://www.brookings.edu/research/global-metro-monitor/ [Accessed: 25/6/2019]

Carolee, B., Heather, C. (2014) "Shaping the Future We Want. UN Decade of Education for Sustainable Development (2005-2014)", United Nations Educational, Scientific and Cultural Organization, Paris, France. [online] Available at: https://unesdoc.unesco.org/ ark:/48223/pf0000230171 [Accessed: 10 June 2019]

Chen, C., Gong, H., Paaswell, R. (2008) "Role of the built environment on mode choice decisions: additional evidence on the impact of density", Transportation, 35(3), pp. 285-299. https://doi.org/10.1007/s11116-007-9153-5

Città Metropolitana di Bologna "I numeri di Bologna metropolitana", [online] Available at: http://www.inumeridibolognametropolitana. it/dati-statistici [Accessed: 15 June 2019] (in Italian)

Citypopulation "City population: Population statistics for countries, administrative divisions, cities, urban areas and agglomerations interactive maps and charts", [online] Available at: www.citypopulation.de [Accessed: 15 June 2019]

Clery, E., Rhead, R. (2013) "Education and attitudes towards the environment", The paper commissioned for the EFA Global Monitoring Report 2013/4, Teaching and learning: Achieving quality for all, UNESCO, 2014/Ed/EFA/MRT/PI/04.4. [online] Available at: https://unesdoc.unesco.org/ark:/48223/pf0000225928 [Accessed: 5 June 2019]

Coll, M. H., Vandersmissen, M.-H., Thériault, M. (2014) "Modeling spatio-temporal diffusion of carsharing membership in Québec City", Journal of Transport Geography, 38, pp. 22-37. https://doi.org/10.1016/j.jtrangeo.2014.04.017

Crane, R. (2000) "The Influence of Urban Form on Travel: An Interpretive Review", Journal of Planning Literature, 15(1), pp. 3-23. https://doi.org/10.1177/08854120022092890

Development Bank of Latin America (CAF) "CAF webpage", [online] Available at: https://www.caf.com/es/conocimiento/datos [Accessed: 15 June 2019]

Dias, F. F., Lavieri, P. S., Garikapati, V. M., Astroza, S., Pendyala, R. M., Bhat, C. R. (2017) "A behavioral choice model of the use of car-sharing and ride-sourcing services", Transportation, 44(6), pp. $1307-1323$

https://doi.org/10.1007/s11116-017-9797-8 citizens is an important path to reduce car dependency and to take down cultural biases. Educating citizens can be used as an important tool to provide modal shift towards sustainable transportation modes.

Dingil, A. E., Schweizer, J., Rupi, F., Stasiskiene, Z. (2018) "Transport indicator analysis and comparison of 151 urban areas, based on open source data", European Transport Research Review (ETRR), 10(2), Article number: 58 https://doi.org/10.1186/s12544-018-0334-4

Dingil, A. E., Schweizer, J., Rupi, F., Stasiskiene, Z. (2019a) "Updated Models of Passenger Transport Related Energy Consumption of Urban Areas", Sustainability, 11(15), Article number: 4060 https://doi.org/10.3390/su11154060

Dingil, A. E., Rupi, F., Schweizer, J., Stasiskiene, Z., Aalipour, K. (2019b) "The Role of Culture in Urban Travel Patterns: Quantitative Analyses of Urban Areas Based on Hofstede's Culture Dimensions", Social Sciences., 8(8), Article number: 227. https://doi.org/10.3390/socsci8080227

European Platform on Mobility Management "EPOMM webpage", [online] Available at: http://www.epomm.eu/tems/result_city.phtml?city=341\&list=1 [Accessed: 15 June 2019]

Eurostat "Eurostat: Your key to European statistics", [online] Available at: https://ec.europa.eu/eurostat/web/cities/data/database [Accessed: 15 June 2019]

Ewing, R., Cervero, R. (2010) "Travel and the Built Environment", Journal of the American Planning Association, 76(3), pp. 265-294. https://doi.org/10.1080/01944361003766766

Feinstein, L., Sabates, R., Anderson, T. M., Sorhaindo, A., Hammond, C. (2006) "What Are the Effects of Education on Health?", In: Measuring the Effects of Education on Health and Civic Engagement, OECD Copenhagen Symposium, Copenhagen, Denmark, pp. 117-354. [online] Available at: http://www.oecd.org/ education/innovation-education/measuringtheeffectsofeducationonhealthandcivicengagement.htm [Accessed: 10 June 2019]

Fietsberaad (2009) "Bicycle policies of the European principals: continuous and integral", Fietsberaad, Utrecht, Netherland, [online] Available at: https://www.cycling-embassy.org.uk/document/bicycle-policies-european-principals-continuous-and-integral-publication-7-2nd-edition [Accessed: 20 June 2019]

Garvill, J., Marell, A., Nordlund, A. (2003) "Effects of increased awareness on choice of travel mode", Transportation, 30, pp. 63-79. https://doi.org/10.1023/A:1021286608889

Handy, S. (1996) "Methodologies for exploring the link between urban form and travel behaviour", Transportation Research Part D: Transport and Environment, 1(2), pp. 151-165. https://doi.org/10.1016/S1361-9209(96)00010-7

Handy, S. L., Xing, Y., Buehler, T. J. (2010) "Factors associated with bicycle ownership and use: a study of six small U.S. cities", Transportation, 37(6), pp. 967-985 https://doi.org/10.1007/s11116-010-9269-x

Hauke, J., Kossowski, T. (2011) "Comparison of alues of Pearson's and Spearman's Correlation Coefficients on the Same Sets of Data", Quaestiones Geographicae, 30(2), pp. 87-93. https://doi.org/10.2478/v10117-011-0021-1 
Hensher, D. A., Rose, J. M. (2007) "Development of commuter and non-commuter mode choice models for the assessment of new public transport infrastructure projects: A case study", Transportation Research Part A: Policy and Practice, 41(5), pp. 428-443. https://doi.org/10.1016/j.tra.2006.09.006

Hofstede, G. (1980) "Culture's Consequences: International Differences in Work-Related Values", Sage, Newbury Park, CA, USA.

Hunecke, M., Blöbaum, A., Matthies, E., Höger, R. (2001) "Responsibility and Environment: Ecological Norm Orientation and External Factors in the Domain of Travel Mode Choice Behavior", Environment and Behavior, 33(6), pp. 830-852. https://doi.org/10.1177/00139160121973269

International Energy Agency (IEA) (2011) " $\mathrm{CO}_{2}$ Emissions from Fuel Combustion: Highlights", International Energy Agency, Paris, France. [online] Available at: https://www.osti.gov/etdeweb/servlets/purl/21589332 [Accessed: 15 June 2019]

Khreis, H., Kelly, C., Tate, J., Parslow, R., Lucas, K., Nieuwenhuijsen, M. (2017) "Exposure to traffic-related air pollution and risk of development of childhood asthma: A systematic review and meta-analysis", Environment International, 100, pp. 1-31. https://doi.org/10.1016/j.envint.2016.11.012

Klöckner, C. A., Matthies, E. (2004) "How habits interfere with norm $\square$ directed behaviour: A normative decision $\square$ making model for travel mode choice", Journal of Environmental Psychology, 24(3), pp. $319-327$. https://doi.org/10.1016/j.jenvp.2004.08.004

Klöckner, C. A., Blöbaum, A. (2010) "A comprehensive action determination model: Toward a broader understanding of ecological behavior using the example of travel mode choice", Journal of Environmental Psychology, 30(4), pp. 574-586. https://doi.org/10.1016/j.jenvp.2010.03.001

Land Transport Authority (2014) "Passenger Transport Mode Shares in World Cities", Journeys, 12, pp. 54-64. [online] Available at: http://www.lta.gov.sg/ltaacademy/doc/J14Nov_p54ReferenceModeShares.pdf [Accessed: 25 June 2019]

Limtanakool, N., Dijst M., Schwanen, T. (2006) "The influence of socioeconomic characteristics, land use and travel time considerations on mode choice for medium- and longer-distance trips", Journal of Transport Geography, 14(5), pp. 327-341. https://doi.org/10.1016/j.jtrangeo.2005.06.004

Matthies, E., Kuhn, S., Klöckner, C. A. (2002) "Travel Mode Choice of Women: The Result of Limitation, Ecological Norm, or Weak Habit?", Environment and Behavior, 34(2), pp. 163-177. https://doi.org/10.1177/0013916502034002001
Mattisson, K., Idris, A. O., Cromley, E., Håkansson, C., Östergren, P. O., Jakobsson, K. (2018) "Modelling the association between health indicators and commute mode choice: a cross-sectional study in southern Sweden", Journal of Transport and Health, 11, pp. 110-121. https://doi.org/10.1016/j.jth.2018.10.012

National Statistics Center, Japan "e-Stat: Portal Site of Official Statistics of Japan", [online] Available at: https://www.e-stat. go.jp/en/stat-search/files?page=1\&query=education $\% 202010 \% 20$ TOKYO\&layout $=$ dataset\&toukei $=00200521$ [Accessed: 25 June 2019]

Plaut, P. O. (2005) "Non-motorized commuting in the US", Transportation Research Part D: Transport and Environment, 10(5), pp. 347-356. https://doi.org/10.1016/j.trd.2005.04.002

Santos, G., Maoh, H., Potoglou, D., von Brunn, T. (2013) "Factors influencing modal split of commuting journeys in medium-size European cities", Journal of Transport Geography, 30, pp. 127-137. https://doi.org/10.1016/j.jtrangeo.2013.04.005

Schwanen, T., Dijst, M., Dieleman, F. M. (2001) "Leisure trips of senior citizens: determinants of modal choice", Tijdschrift voor economische en sociale geografie, 92(3), pp. 347-360. https://doi.org/10.1111/1467-9663.00161

Seoul Metropolitan Government "Seoul Statistics by Category", [online] Available at: http://english.seoul.go.kr/get-to-know-us/statistics-of-seoul/seoul-statistics-by-category/ [Accessed: 25/6/2019]

Sootfreecities "Dataset", [online] Available at: http://www.sootfreecities. eu/sootfreecities.eu/public/measure/traffic-mobility [Accessed: 15 June 2019]

Ton, D., Duives, D. C., Cats, O., Hoogendoorn-Lanser, S., Hoogendoorn, S. P. (2019) "Cycling or walking? Determinants of mode choice in the Netherlands", Transportation Research Part A: Policy and Practice, 123, pp. 7-23.

https://doi.org/10.1016/j.tra.2018.08.023

United States Census Bureau "American Fact Finder", [online] Available at: https://factfinder.census.gov/faces/nav/jsf/pages/searchresults. xhtml?refresh $=t$ [Accessed: 15 June 2019]

Van der Borg, J., Russo, A. P. (2005) "The Impacts of Culture on the Economic Development of Cities", European Institute for Comparative Urban Research (EURICUR), Rotterdam, Netherland. [online] Available at: https://www.wien.gv.at/meu/fdb/pdf/ intern-vergleichsstudie-ci-959-ma27.pdf [Accessed: 25 June 2019]

Vasconcellos, E. A. de (2005) "Urban change, mobility and transport in São Paulo: three decades, three cities", Transport Policy, 12(2), pp. 91-104.

https://doi.org/10.1016/j.tranpol.2004.12.001 